\title{
iAudiometry: Comparison and Verification of a Interactive Audiometer for iPad for Audiological Screening in Occupational Medicine
}

\author{
L Cirrincione ${ }^{1}$, E Lo Pinto ${ }^{2}$, S Casà ${ }^{3}$ and E Cannizzaro ${ }^{4 *}$ \\ ${ }^{1}$ Specializing in Occupational Medicine, Italy \\ ${ }^{2}$ Specialist in Sport Medicine, Italy
}

${ }^{3}$ Student in degree course of prevention technicians, Italy

${ }^{4}$ Department of Sciences for Health Promotion and Mother and Child Care “Giuseppe D’Alessandro", University of Palermo, Italy

*Corresponding author: E Cannizzaro, Department of Sciences for Health Promotion and Mother and Child Care "Giuseppe

D’Alessandro", University of Palermo, Italy

\begin{tabular}{|c|c|}
\hline ARTICLE INFO & ABSTRACT \\
\hline Received: 幽 November 27, 2019 & Citation: L Cirrincione, E Lo Pinto, S Casà, E Cannizzaro. iAudiometry: Comparison and \\
\hline Published: 慧December 18, 2019 & $\begin{array}{l}\text { Verification of an Interactive Audiometer for iPad. Biomed J Sci \& Tech Res 24(1)-2019. } \\
\text { BJSTR. MS.ID.003981. }\end{array}$ \\
\hline
\end{tabular}

\section{Introduction}

The recent development of communication technologies such as smartphones and tablets, has paved the way for the implementation of applications, by exploiting the potential of devices, making it possible to combine expensive instruments, which until recently were only very effective tools, but certainly less expensive. This is a tool that can be used to replace a medical device such as an audiometer demonstrates just what has just been said. The iAudiometry application development project is born of the union of three different disciplines, applied acoustics, computer programmer and medicine. The following characteristics are based on their skills. Precision comparable to professional equipment of the same type; very low cost compared to traditional instruments; Possibility of use in any place thanks to the portability of the device - Tool open to continuous updates and improvements. The main trigger for hearing loss is age. Over the years, in fact, the hearing ability is reduced in all people due to the attrition of the hair cells placed in the inner ear, so it is completely normal to suffer from a form of hearing loss called presbycusis.

Among the etiological factors, the most widespread in adults, besides aging, is occupational risk. Prolonged exposure to noise at high intensities in the workplace over time can cause adverse health effects, including permanent impairment of hearing or noise-induced hearing loss; tinnitus, the continuous perception over time of an abnormal noise, perceived in one or both ears, in the absence of an external sound. Finally, it should be remembered that other external phenomena can participate in aggravating hearing damage, between these high levels of stress and anxiety that interrupt the normal pattern of cortisol plasma levels in healthy subjects, resulting in a significant reduction in cardio-vascular parameters [1], which can cause damage to the inner ear.

Hearing loss due to exposure to noise can also be aggravated by the usual use of various drugs or chemical compounds that often share the same ototoxic mechanisms of noise. However, there is great variability in the individual's response to a given xenobiotic that depends on a complex interaction between endogenous and exogenous factors [2]. To prevent damage, the competent doctor establishes health protocols that provide screening tests to be performed on all workers of the same homogeneous group and diagnostic investigations to be carried out on symptomatic workers.

Complementary health checks must be aimed at the functional exploration of the organs specifically exposed to the risk factor [3]. In the case of workers exposed to the risk of noise, these will be subjected to a liminal tonal audiometry, a first level examination to identify the onset of symmetrical bilateral sensorineural hearing 
loss; it is characterized by a particular audiometric tracing, which makes it possible to distinguish it from other ear pathologies, often the execution of this examination involves considerable difficulties in being able to transport and use diagnostic tools in the workplace, as more and more often the medicine of modern labor requires. Hearing loss is a disease that can depend on multiple causes, including advanced age, heredity, high intensity noise exposure, drug use, alcohol, smoking and stress [4]. Among the etiological factors, the most widespread in adults, besides aging, is occupational risk. Prolonged exposure to noise at high intensities in the workplace over time can cause adverse health effects, including permanent impairment of hearing or noise-induced hearing loss; tinnitus, the continuous perception over time of an abnormal noise, perceived in one or both ears, in the absence of an external sound.

\section{Targets}

The court examined 68 normoacusic subjects and a further group of 22 construction workers with hearing loss from both noise and presbycusis, the data obtained were subsequently analyzed using the statistical method [5].

\section{Materials and Methods}

This work was performed in April 2019, dividing it into two distinct phases. The reliability and stability of the iAudiometry app was first verified by analyzing the signal generated, calibrated using precision instruments classified in class 1 according to the IEC651 standards, such as: (Figures 1 \& 2). This instrumentation allows to have a precision in the acquisition of the signal equal to +/- $0.7 \mathrm{~dB}$. In order to ensure greater precision, it was also decided to perform separate calibrations for the right and left pavilion. These tests were carried out for continuous periods of 120 minutes, in order to verify the constancy of the emitted signal even after prolonged use of the device. Subsequently, a single blind study was conducted, comparing the tonal audiometry in comparative terms in which the analyzed subjects did not know the source of the sound [6-10]. The court examined was composed of a group of 68 normoacusic subjects and a further group of 22 subjects with hearing loss from both noise and presbycusis, the data obtained were subsequently analyzed using the statistical method. The audiometry was performed on the same subject twice, at a distance of 30 minutes between the two exams, using a conventional audiometer of the brand OSCILLA model SM 910, and our app with professional headphones Sennheiser HDA300, loaded on ipad pro year of production 2018 (Figure 3). Finally, it was established that all the subjects participating in the study did not present any diseases affecting the auditory system, the airways, and that they had observed an acoustic rest period from sources of noise for at least 18 hours $[11,12]$.

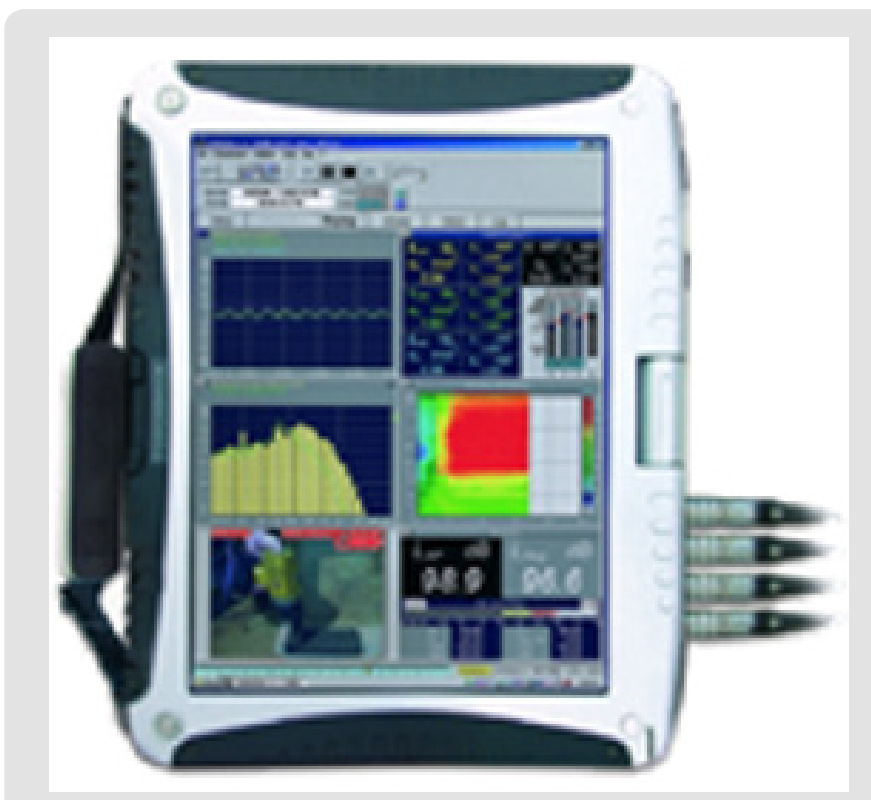

Figure 1: A class 1 analyzer meter 1 sinus soundbook.

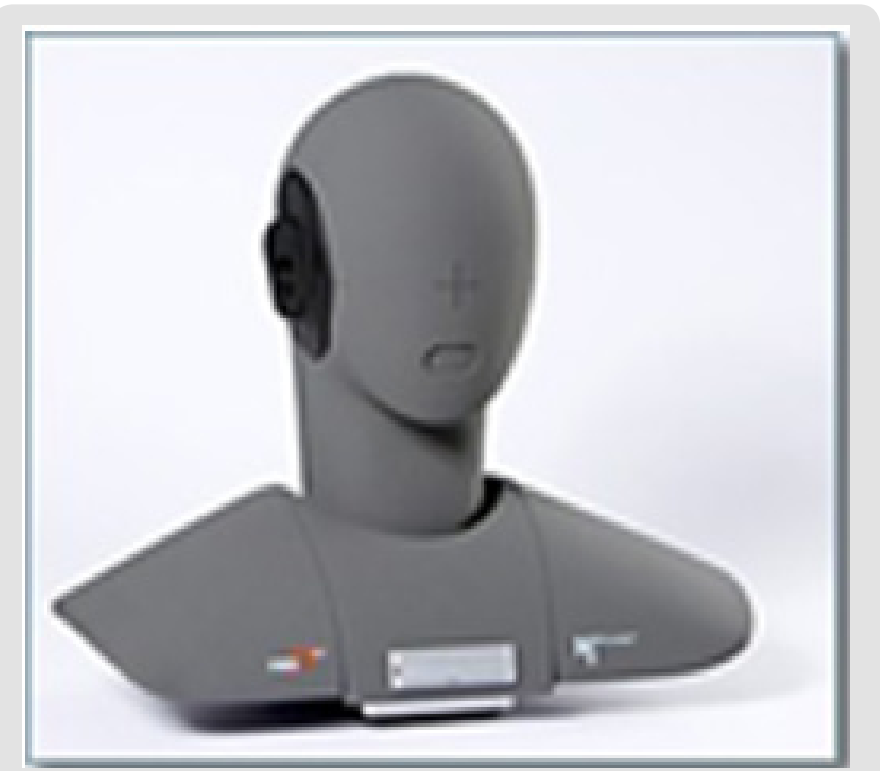

Figure 2: A head acoustic head. 


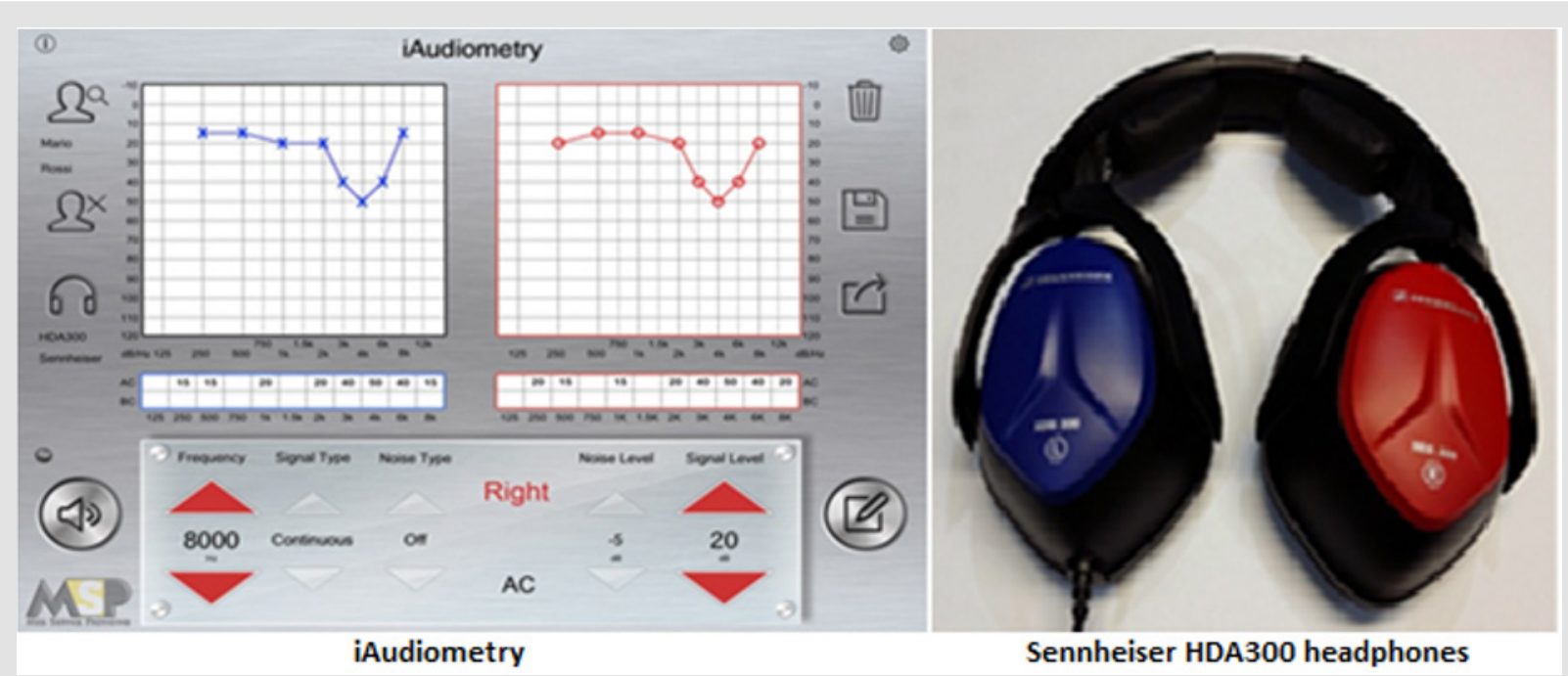

Figure 3.

\section{Results}

The results obtained highlight the following:

1) Between the theoretical signal and the real signal, a dispersion of more than the percentage point was not detected (Figure 4).

2) The differences observed between the values entered in the calibration matrix and the measured values are statistically not relevant (Table 1).

3) The hearing threshold averages, at the different audiometry frequencies, performed on the group of normoacusic subjects showed a difference of $+/-2 \mathrm{~dB}$ (Table 2).

4) The averages of hearing thresholds at the different frequencies of audiometries performed on the group of hearingimpaired subjects (Table 3) [13-15].

\section{Dispersione tra segnale teoricoe segnale reale}

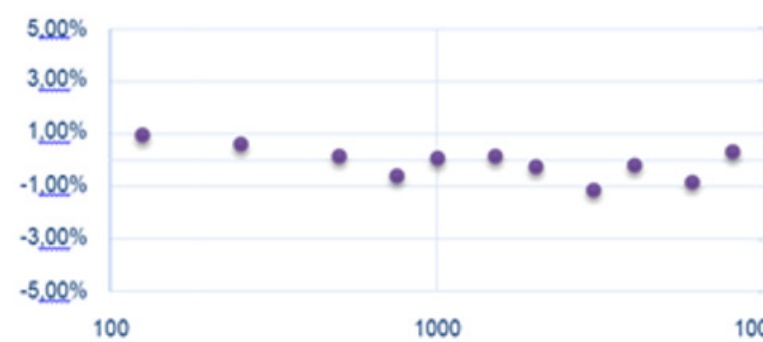

Figure 4: Percentage comparison between the value of theoretical signals and values generated by iAudiometry and Professional Sennheiser HDA 300 headphone.

Table 1: Differences between values entered in the calibration matrix and values measured with Sennheiser HDA300 headphones.

\begin{tabular}{|c|c|c|c|c|c|c|c|c|c|c|c|}
\hline & 125 & 250 & 500 & 750 & 1000 & 1500 & 2000 & 3000 & 4000 & 6000 & 8000 \\
\hline $\begin{array}{c}\mathrm{dB} \text { correct } \\
\text { verification }=\end{array}$ & 83 & 84,5 & 76,5 & 79 & 80,5 & 84,5 & 82 & 66,5 & 79,5 & 73 & 66 \\
\hline $\begin{array}{c}\text { measured } \\
\text { matrix element } \\
=\end{array}$ & 0,175 & 0,114 & 0,031 & 0,031 & 0,026 & 0,0635 & 0,075 & 0,0142 & 0,071 & 0,0276 & 0,0188 \\
\hline \multirow{2}{*}{$\begin{array}{l}\text { matrix element } \\
\text { calculated }\end{array}$} & 0,17391 & 0,11384 & 0,03099 & 0,03086 & 0,02602 & 0,06324 & 0,07558 & 0,01423 & 0,07083 & 0,02751 & 0,01871 \\
\hline & 4966 & 8742 & 2157 & 5659 & 7087 & 9301 & 2914 & 1093 & 9217 & 186 & 9575 \\
\hline error \% & $0,62 \%$ & $0,13 \%$ & $0,03 \%$ & $0,44 \%$ & $-0,10 \%$ & $0,40 \%$ & $-0,77 \%$ & $-0,22 \%$ & $0,23 \%$ & $0,33 \%$ & $0,43 \%$ \\
\hline
\end{tabular}

Table 2.

\begin{tabular}{|c|c|c|c|c|c|c|c|c|c|c|c|c|c|c|c|c|c|c|c|c|c|c|}
\hline & \multicolumn{2}{|c|}{125} & \multicolumn{2}{|c|}{250} & \multicolumn{2}{|c|}{500} & \multicolumn{2}{|c|}{750} & \multicolumn{2}{|c|}{1000} & \multicolumn{2}{|c|}{1500} & \multicolumn{2}{|c|}{2000} & \multicolumn{2}{|c|}{3000} & \multicolumn{2}{|c|}{4000} & \multicolumn{2}{|c|}{6000} & \multicolumn{2}{|c|}{8000} \\
\hline & $\begin{array}{l}\mathbf{S} \\
\mathbf{x}\end{array}$ & $\begin{array}{l}\mathbf{D} \\
\mathbf{x}\end{array}$ & $\begin{array}{l}\mathbf{S} \\
\mathrm{x}\end{array}$ & $\begin{array}{l}\mathbf{D} \\
\mathbf{x}\end{array}$ & $\begin{array}{l}\mathbf{S} \\
\mathrm{x}\end{array}$ & $\begin{array}{l}\mathbf{D} \\
\mathbf{x}\end{array}$ & $\begin{array}{l}\mathrm{S} \\
\mathrm{x}\end{array}$ & $\begin{array}{l}\mathbf{D} \\
\mathbf{x}\end{array}$ & $\begin{array}{l}\mathbf{S} \\
\mathrm{x}\end{array}$ & $\begin{array}{l}\mathbf{D} \\
\mathbf{x}\end{array}$ & $\begin{array}{l}\mathbf{S} \\
\mathrm{x}\end{array}$ & $\begin{array}{l}\mathbf{D} \\
\mathbf{x}\end{array}$ & $\begin{array}{l}\mathrm{S} \\
\mathrm{x}\end{array}$ & $\begin{array}{l}\mathbf{D} \\
\mathbf{x}\end{array}$ & $\mathbf{x}$ & $\begin{array}{l}\mathbf{D} \\
\mathbf{x}\end{array}$ & $\begin{array}{l}\mathbf{S} \\
\mathbf{x}\end{array}$ & $\begin{array}{l}\mathbf{D} \\
\mathbf{x}\end{array}$ & $\begin{array}{l}\mathrm{S} \\
\mathrm{x}\end{array}$ & $\begin{array}{l}\mathbf{D} \\
\mathbf{x}\end{array}$ & $\begin{array}{l}\mathrm{S} \\
\mathrm{x}\end{array}$ & $\begin{array}{l}\mathbf{D} \\
\mathrm{x}\end{array}$ \\
\hline $\begin{array}{l}\text { TEST with } \\
\text { audiometer } \\
\text { traditional }\end{array}$ & 11 & 11 & 10 & 10 & 10 & 9 & 8 & 9 & 10 & 11 & 11 & 12 & 10 & 9 & 9 & 10 & 14 & 13 & 10 & 10 & 9 & 10 \\
\hline
\end{tabular}




\begin{tabular}{|c|c|c|c|c|c|c|c|c|c|c|c|c|c|c|c|c|c|c|c|c|c|c|}
\hline $\begin{array}{c}\text { TEST APP + HAD } \\
300\end{array}$ & 10 & 10 & 11 & 10 & 10 & 8 & 10 & 10 & 9 & 10 & 11 & 11 & 10 & 10 & 8 & 8 & 15 & 13 & 9 & 10 & 9 & 9 \\
\hline Differences: & 1 & 1 & -1 & 0 & 0 & 1 & -2 & -1 & 1 & 1 & 0 & 1 & 0 & -1 & 1 & 2 & -1 & 0 & 1 & 0 & 0 & 1 \\
\hline
\end{tabular}

Table 3.

\begin{tabular}{|c|c|c|c|c|c|c|c|c|c|c|c|c|c|c|c|c|c|c|c|c|c|c|}
\hline & \multicolumn{2}{|c|}{125} & \multicolumn{2}{|c|}{250} & \multicolumn{2}{|c|}{500} & \multicolumn{2}{|c|}{750} & \multicolumn{2}{|c|}{1000} & \multicolumn{2}{|c|}{1500} & \multicolumn{2}{|c|}{2000} & \multicolumn{2}{|c|}{3000} & \multicolumn{2}{|c|}{4000} & \multicolumn{2}{|c|}{6000} & \multicolumn{2}{|c|}{8000} \\
\hline & $\begin{array}{l}\mathbf{S} \\
\mathbf{x}\end{array}$ & $\begin{array}{l}\mathbf{D} \\
\mathbf{x}\end{array}$ & $\begin{array}{l}S \\
\mathbf{x}\end{array}$ & $\begin{array}{l}\mathbf{D} \\
\mathbf{x}\end{array}$ & $\begin{array}{l}\mathbf{S} \\
\mathbf{x}\end{array}$ & $\begin{array}{l}\mathbf{D} \\
\mathbf{x}\end{array}$ & $\begin{array}{l}S \\
\mathrm{x}\end{array}$ & $\begin{array}{l}\text { D } \\
\mathbf{x}\end{array}$ & $\begin{array}{l}S \\
\mathbf{x}\end{array}$ & $\begin{array}{l}\mathbf{D} \\
\mathbf{x}\end{array}$ & $\begin{array}{l}\mathbf{S} \\
\mathbf{x}\end{array}$ & $\begin{array}{l}\mathbf{D} \\
\mathbf{x}\end{array}$ & $\begin{array}{l}S \\
\mathbf{x}\end{array}$ & $\begin{array}{l}\mathbf{D} \\
\mathbf{x}\end{array}$ & $\begin{array}{l}\mathbf{S} \\
\mathbf{x}\end{array}$ & $\begin{array}{l}\text { D } \\
\mathbf{x}\end{array}$ & $\begin{array}{l}\mathbf{S} \\
\mathbf{x}\end{array}$ & $\begin{array}{l}\mathbf{D} \\
\mathbf{x}\end{array}$ & $\begin{array}{l}\mathbf{S} \\
\mathbf{x}\end{array}$ & $\begin{array}{l}\mathbf{D} \\
\mathbf{x}\end{array}$ & $\begin{array}{l}\mathbf{S} \\
\mathbf{x}\end{array}$ & $\begin{array}{l}\text { D } \\
\mathbf{x}\end{array}$ \\
\hline $\begin{array}{l}\text { TEST with } \\
\text { audiometer } \\
\text { traditional }\end{array}$ & 12 & 11 & 10 & 10 & 10 & 11 & 8 & 9 & 15 & 15 & 14 & 13 & 21 & 22 & 25 & 24 & 27 & 31 & 28 & 26 & 20 & 20 \\
\hline $\begin{array}{c}\text { TEST APP + HAD } \\
300 \\
\end{array}$ & 11 & 10 & 11 & 8 & 10 & 10 & 9 & 9 & 13 & 14 & 14 & 13 & 19 & 21 & 24 & 25 & 27 & 30 & 28 & 28 & 20 & 20 \\
\hline Differences: & 1 & 1 & -1 & 2 & 0 & 1 & -1 & 0 & 2 & 1 & 0 & 0 & 2 & 1 & 1 & -1 & 0 & 1 & 0 & -2 & 0 & 0 \\
\hline
\end{tabular}

\section{Conclusion}

It is well known that tonal audiometry, an examination of the auditory capacity performed by means of an electrical apparatus called an audiometer, allows us to assess the auditory threshold, that is the minimum perceivable intensity for sounds of various frequencies, in a simple and correct manner, at least at first pre-diagnosis. The patient in question is offered different sine frequency electronic waves through headphones, bone conduction headphones and loudspeakers. The objective of our study was to evaluate the functionality of our iAudiometry application, a very simple and intuitive system for performing audiometric screening, with extreme versatility and portability, being loadable on devices marketed by Apple under the name of Ipad. We verified its accuracy and reliability both through the use of precision instruments such as an analyzer sound level meter in class 1 sinus soundbook and a head acoustic acoustic head, as well as performing a clinical study in single blind to verify the reliability of the audiometries obtained.

The results showed us how, at the end of the design and implementation process, iAudiometry was a comparable application for the audiological sector to conventional audiometers; showing no statistically significant difference, for the normal frequencies used, during the execution of the audiometric examination. Even the prolonged and continuous use of the application has not shown any alteration in the calibration and in the intensity of the sound emitted. In conclusion, iAudiometry can be used as a screening tool for hearing impairments, in the same way as any conventional audiometer on the market, with a portability and a considerable economic advantage.

\section{References}

1. Martines F, Sireci F, Cannizzaro E, Costanzo R, Martines E, et al. (2015) Clinical observations and risk factors for tinnitus in a Sicilian cohort. Eur Arch Otorhinolaryngol 272(10): 2719-2729.

2. Leonardo Soleo, Emanuele Cannizzaro, Piero Lovreglio, Basso A, D’Errico MN, et al. (2013) Protocols for the health surveillance of fisherman. Italian Journal of Occupational Medicine and Ergonomics 35(4): 222226.
3. Mucia M, Salvago P, Brancato A, Cannizzaro C, Cannizzaro E, et al. (2015) Upper Respiratory Tract Infections in Children: From Case History to Management. Acta Medica Mediterranea 31: 419.

4. Cannizzaro E, Ramaci T, Cirrincione L, Fulvio Plescia (2019) Workrelated stress, physio-pathological mechanisms, and the influence of environmental genetic factors. International Journal of Environmental Research and Public Health 16(20): 4031.

5. Cannizzaro E, Cannizzaro C, Plescia F, Francesco M, Leonardo S, et al. (2014) Exposure to ototoxic agents and hearing loss: A review of current knowledge. Hearing Balance and Communication 12(4): 166-175.

6. Martines F, Sireci F, Cannizzaro E, Costanzo R, Martines E, et al. (2015) Clinical observations and risk factors for tinnitus in a Sicilian cohort. Eur Arch Otorhinolaryngol 272(10): 2719-2729.

7. Cavallaro A, Martines F, Cannizzaro C, Gianluca L, Anna B, et al. (2016) Role of cannabinoids in the treatment of tinnitus. Acta Medica Mediterr 32(4): 903-909.

8. Ballacchino A, Salvago P, Cannizzaro E, Robert A, Maurizio Di M, et al. (2015) Association Between Sleep-Disordered Breathing and Hearing Disorders: Clinical Observation in Sicilian Patients. Acta Medica Mediterranea 31: 607.

9. Cannizzaro E, Cannizzaro C, Martorana D, Moscadini S, Daniele Lo C (2012) Effects of shift work on cardiovascular activity, serum cortisol and white blood cell count in a group of Italian fishermen. EuroMediterranean Biomedical Journal 2012(3): 109-113.

10. Cannizzaro E, Plescia F, Cirrincione L, Lo Pinto E, Plescia F (2018) Sport for job. Differences in cortisol levels in a water polo team at different times of workout. EuroMediterranean Biomedical Journal 13(41): 181184.

11. Plescia F, Cannizzaro C, Brancato A (2016) Emerging Pharmacological Treatments of Tinnitus. Otolaryngology Research Advaces. Tinnutus - Epidemiology, Causes and Emerging Therapeutic Treatments. NOVA Biomedical.

12. Beck RM, Ramos BF, Grasel SS, Ramos HF, Moraes MF, et al. (2014) Comparative study between pure tone audiometry and auditory steady-state responses in normal hearing subjects. Brazilian Journal of Otorhinolaryngology 80(1): 35-40.

13. Jung EK, Choi YM, Kim EJ, Lee S, Cho HH (2019) Development of sound field audiometry system for small audiometric booths and comparison of its equivalence with traditional system. Clinical and Experimental Otorhinolaryngology.

14. Thoidis I, Vrysis L, Markou K, Papanikolaou G (2019) Development and evaluation of a tablet-based diagnostic audiometer. Int J Audiol 58(8): 476-483.

15. Corry M, Sanders M, Searchfield GD (2017) The accuracy and reliability of an app-based audiometer using consumer headphones: pure tone audiometry in a normal hearing group. Int J Audiol 56(9): 706-710. 


\section{ISSN: 2574-1241}

DOI: $10.26717 /$ BJSTR.2019.24.003981

E Cannizzaro. Biomed J Sci \& Tech Res

(C) This work is licensed under Creative

Submission Link: https://biomedres.us/submit-manuscript.php

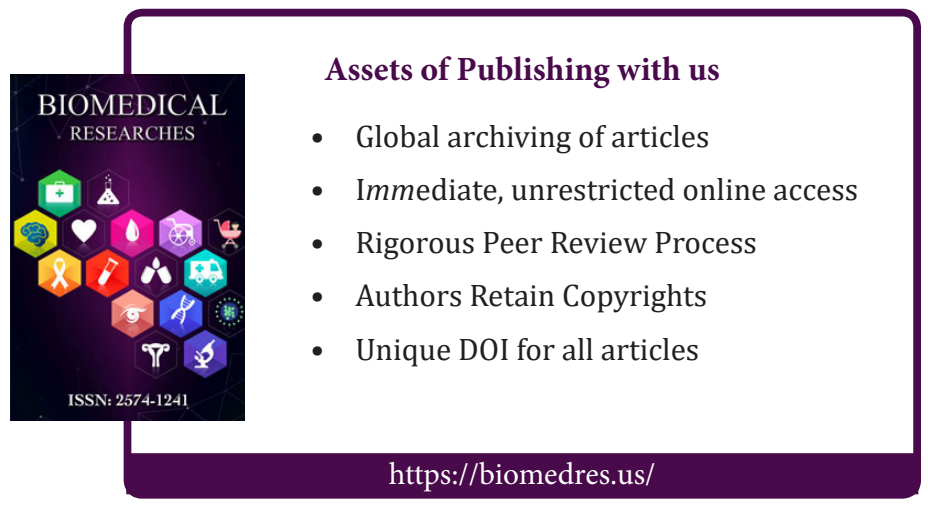

